\title{
Insensitive cation effect on single-atom Ni catalyst allows selective electrochemical conversion of captured $\mathrm{CO} 2$ in universal media
}

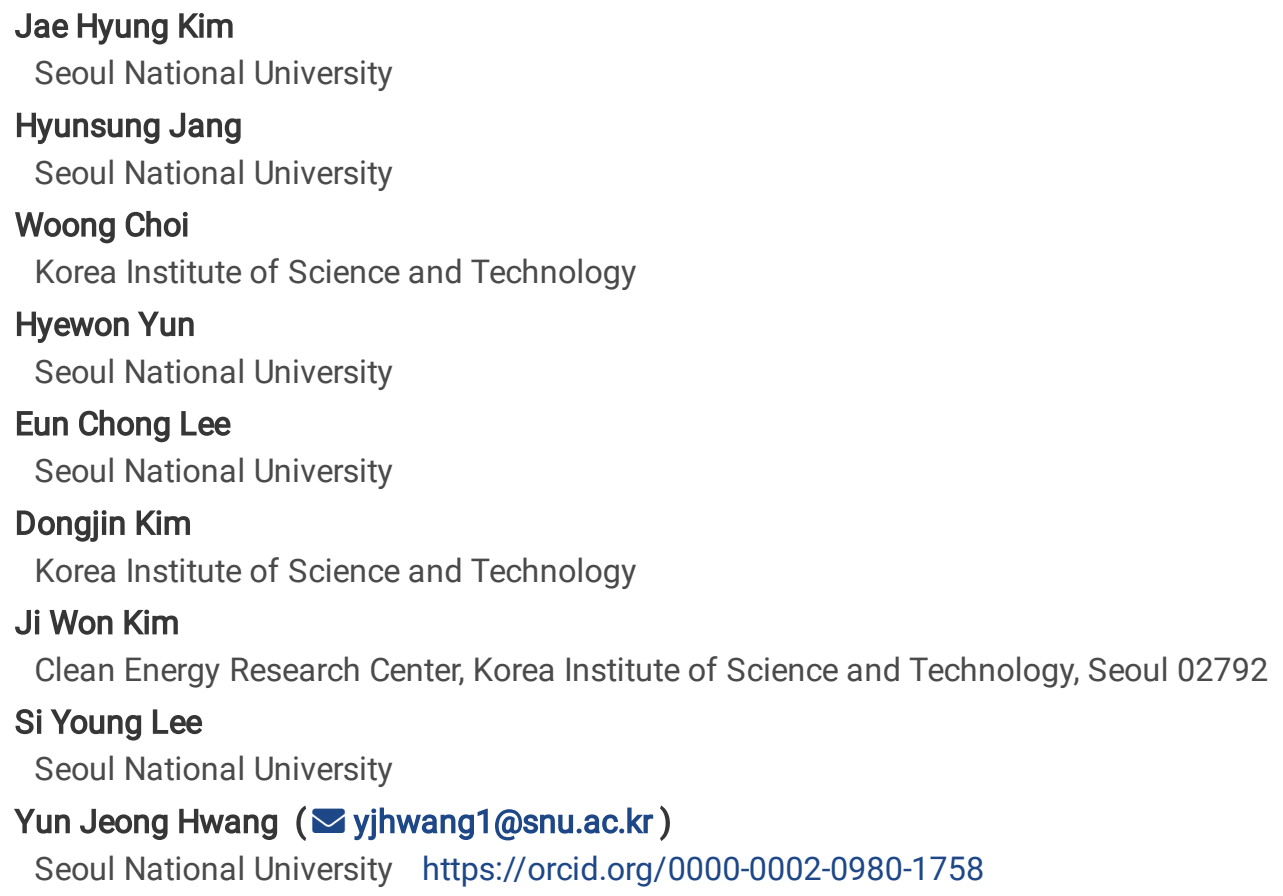

Article

Keywords:

Posted Date: February 18th, 2022

DOI: https://doi.org/10.21203/rs.3.rs-1310811/v1

License: @ (i) This work is licensed under a Creative Commons Attribution 4.0 International License. Read Full License 


\section{Abstract}

The direct electroconversion of captured $\mathrm{CO} 2$ is attracting attention as an alternative to the current energy-demanding $\mathrm{CO} 2$ separation processes. In conventional capturing media, the reaction inevitably takes place in the presence of bulky ammonium, leading to steric hindrance and low $\mathrm{CO}$ selectivity. Here, for the first time, we present a single atom $\mathrm{Ni}$ catalyst (Ni-N/C) exhibits superior activity for the electroconversion of captured $\mathrm{CO}$, without the need for additives. In a CO2-captured monoethanolamine-based electrolyte, Ni-N/C achieves a notably high $\mathrm{CO}$ selectivity of $64.9 \%$ at $-50 \mathrm{~mA} \mathrm{~cm}-2$ integrated with a membrane electrode assembly. We also propose that $\mathrm{Ni}-\mathrm{N} / \mathrm{C}$ demonstrates weak cation sensitivity to the $\mathrm{CO} 2$ reduction reaction, maintaining high $\mathrm{CO}$ production activity in various capturing solutions, while Ag shows a gradual decrease depending on the bulkiness of the amine. These trends provide insights into selective catalyst design for the electroconversion of captured $\mathrm{CO} 2$ in universal media.

\section{Introduction}

Severe climate changes caused by anthropogenic carbon emissions have steered a global consensus toward carbon neutrality. ${ }^{1-3}$ Accordingly, the development of efficient carbon capture, utilization, and storage (CCUS) technology has been recognized as one of the most urgent technologies to sustainable societies. ${ }^{4,5} \mathrm{CO}_{2}$ from exhaust gases can be selectively captured using a basic solvent to which $\mathrm{CO}_{2}$ can be readily bound as carbamate or bicarbonate, and the captured $\mathrm{CO}_{2}$ is separated either by thermal or pressure swings

for utilization. ${ }^{6,7}$ However, the regeneration processes are energy-intensive, imposing a huge penalty on the operating cost of the overall CCUS processes. ${ }^{8,9}$ Moreover, during the high-temperature stripping operation, amine-based capturing media suffer from oxidative and thermal degradation. ${ }^{10,11}$ To overcome these drawbacks, the direct utilization of captured $\mathrm{CO}_{2}$, which omits the $\mathrm{CO}_{2}$ separation step, has been evaluated to enhance the feasibility of CCUS. ${ }^{12-15}$

The direct electroconversion via the captured- $\mathrm{CO}_{2}$ reduction reaction $\left(\mathrm{CCO}_{2} \mathrm{RR}\right)$ has been proposed utilizing the $\mathrm{CO}_{2}$ absorption media as the electrolyte (Fig. 1a). ${ }^{16-27}$ However, inferior selectivity toward $\mathrm{CO}$ or formate has been exhibited compared with that of the conventional $\mathrm{CO}_{2}$-fed electrochemical reduction reaction $\left(\mathrm{CO}_{2} \mathrm{RR}\right) \cdot{ }^{28}$ The electrocatalytic activity is determined by the charge transfer at the electrode-electrolyte interface, which necessitates the thorough investigation of $\mathrm{cCO}_{2} \mathrm{RR}$ in terms of the interactions with the absorbent medium to improve the conversion activity. Yet, it is still in the early stages of research, and the previous studies have focused either on the fundamental catalyst material itself or the electrolyzer configuration. The low CO production from electroreduction of the bicarbonate has recently been tackled by using a bipolar membranes (BPM) to develop a proton-rich environment in the vicinity of the cathode in a membrane electrode assembly. The acidified environment helps the chemical equilibrium shift in favor of $\mathrm{CO}_{2}$ by the following reaction (Equation (1)):

$$
\mathrm{CO}_{2}+\mathrm{H}_{2} \mathrm{O} \rightleftharpoons \mathrm{H}_{2} \mathrm{CO}_{3} \rightleftharpoons \mathrm{H}^{+}+\mathrm{HCO}_{3}^{-}
$$

This increases the local $\mathrm{CO}_{2}$ concentration near the cathode and promotes $\mathrm{CO}$ production. Such a strategy, however, has been demonstrated in the bicarbonate electrolyte.

The industrial-standard $\mathrm{CO}_{2}$ capturing medium is a $30 \mathrm{wt}$ \% monoethanolamine (MEA) aqueous solution that has a higher $\mathrm{CO}_{2}$ absorption capacity and kinetics. ${ }^{24}$ Unfortunately, the selective $\mathrm{CCO}_{2} \mathrm{RR}$ has been more challenging in MEA-based electrolytes, in which $\mathrm{CO}_{2}$ forms bulky ions, e.g.,

$2 \mathrm{HOC}_{2} \mathrm{H}_{2} \mathrm{NH}_{2}+\mathrm{CO}_{2} \rightleftharpoons \mathrm{HOC}_{2} \mathrm{H}_{2} \mathrm{NH}_{3}^{+}+\mathrm{HOC}_{2} \mathrm{H}_{2} \mathrm{NHCOO}^{-}$

The bulky cations can construct an electric double layer (EDL) at the cathode surface, which hinders the $\mathrm{CCO}_{2} \mathrm{RR}^{26,29}$ It has been proposed that alkali metal salts, which have a smaller effective cation radius and allow better access to captured $\mathrm{CO}_{2}$ on the catalyst surface, are required to achieve the $\mathrm{CO}$ production in the $\mathrm{CCO}_{2} \mathrm{RR} .{ }^{26}$ However, in pure amine-based absorbent media with no metal salt additives, poor $\mathrm{CO}$ production has still been observed (Supplementary Table 1) and further research is required to understand this activity. Furthermore, in the practical $\mathrm{CO}_{2}$ capture process, a wide range of amine-based solvent formulations has been exploited to enhance the $\mathrm{CO}_{2}$ absorption or regeneration rate. ${ }^{30}$ Therefore, understanding universal performance in diverse capturing media is important in bringing the immediate applications of the $\mathrm{CCO}_{2} \mathrm{RR}$ to industry. 
To attain high $\mathrm{CO}$ selectivity in practical $\mathrm{CO}_{2}$ capturing media, it is also necessary to find active electrode materials and investigate its interaction with the electrolyte. Thus far, only metal catalysts have been utilized for the $\mathrm{CCO}_{2} \mathrm{RR}$ (Supplementary Table 1). In the last decade, single atom catalysts (SACs), where metal atoms are fully dispersed on supports, have been explosively studied and an unprecedented catalytic reactivity has been exhibited for various catalytic reactions. ${ }^{31}$ Single atom Ni catalysts embedded in N-doped carbon $\left(\mathrm{Ni}-\mathrm{N} / \mathrm{C}\right.$ ) have shown particularly impressive $\mathrm{CO}_{2} \mathrm{RR}$ activity and selectivity toward $\mathrm{CO}$ compared to metal catalysts in suppressing the hydrogen evolution reaction (HER). ${ }^{32,33}$ Moreover, the dominant carbon matrix of $\mathrm{Ni}-\mathrm{N} / \mathrm{C}$ would manifest the differing potential of zero charge (PZC) with a metal electrode. Such differences can affect the formation of the EDL, which would be effective in modulating the electrode-electrolyte interface for improving the performance of the $\mathrm{CCO}_{2} \mathrm{RR}$. Nevertheless, SACs have never been examined for the $\mathrm{CCO}_{2} \mathrm{RR}$.

Here, we demonstrate that the low cation sensitivity of the $\mathrm{Ni}-\mathrm{N} / \mathrm{C}$ catalyst allows the selective $\mathrm{CCO}_{2} \mathrm{RR}$ in universal $\mathrm{CO}_{2}$-capturing media, even in the exclusive presence of bulky cations. In $\mathrm{CO}_{2}$-captured MEA, the maximum $\mathrm{CO}$ faradaic efficiency (F. E.) of Ni-N/C $(63.2 \%)$ is superior to that of commercial Ag nanoparticles (cAg, 30.1\%), and the maximum CO partial current density (jco) of $\mathrm{Ni}-\mathrm{N} / \mathrm{C}$ $\left(-3.5 \mathrm{~mA} \mathrm{~cm}^{-2}\right)$ is three times higher than that of $\mathrm{cAg}\left(-0.9 \mathrm{~mA} \mathrm{~cm}^{-2}\right)$ in the H-cell. In the zero-gap membrane electrode assembly configuration, the CO F. E. of Ni-N/C (64.9\%) is 2.5 times higher than that of $\mathrm{cAg}(25.5 \%)$ at $-50 \mathrm{~mA} \mathrm{~cm}{ }^{-2}$, which is the highest performance ever reported in $\mathrm{CO}_{2}$-captured MEA solution without additives. We further report that $\mathrm{Ni}-\mathrm{N} / \mathrm{C}$ can maintain the $\mathrm{CO} F$. E. at as much as $50 \%$, even in bulkier amine solutions, in contrast to cAg, where the $\mathrm{CO} F$. E. gradually falls to $0 \%$ with increasing amine bulkiness. Through a cation control experiment, we identify that the reactivity of $\mathrm{Ni}-\mathrm{N} / \mathrm{C}$ for the $\mathrm{CO}_{2} \mathrm{RR}$ is less influenced by the size of the cation compared with that of cAg. We propose that a high surface charge density induced by the positive-shifted PZC of Ni-N/C allows for a marginal cation effect, which enables the maintenance of high $\mathrm{CO}$ selectivity in bulky amine-based electrolytes, in addition to the excellent suppression of HER of Ni-N/C. To the best of our knowledge, this is the first report of a catalytic approach relieving the cation effect, which permits the universal electroconversion of captured $\mathrm{CO}_{2}$.

\section{Results}

Preparation and characterization of $\mathrm{Ni}-\mathrm{N} / \mathrm{C}$. The $\mathrm{Ni}-\mathrm{N} / \mathrm{C}$ catalyst was prepared by the thermal conversion of zeolitic imidazolate framework (ZIF)-8, with some modifications to previous work. ${ }^{34}$ ZIF-8 was synthesized through the self-assembly of $\mathrm{Zn}^{2+}$ and imidazolate with a particle size of $\sim 100 \mathrm{~nm}$ (Supplementary Fig. 1); Zn was replaced with Ni by ion-exchange. The resulting light-green powder was then carbonized at $1000^{\circ} \mathrm{C}$ to produce a final product, $\mathrm{Ni}-\mathrm{N} / \mathrm{C}$. Scanning electron microscopy (SEM) and transmission electron microscopy (TEM) images of Ni-N/C displayed rather contracted morphologies compared to ZIF-8 after high-temperature treatment (Supplementary Fig. 2). ${ }^{35}$ From high-angle annular dark-field scanning transmission electron microscopy (HAADF-STEM) images of Ni-N/C (Fig. 1b and Supplementary Figs. 2c and d), bright dots can be observed on the support, indicating the generation of atomically dispersed $\mathrm{Ni}$ sites embedded on the N-doped carbon matrix without any agglomerated metal particles (Supplementary Fig. 3). Extended X-ray absorption fine structure (EXAFS) analysis confirms the structural information seen in the microscopy images (Fig. 1c). The Ni K-edge $k^{3}$-weighted extended EXAFS spectrum of Ni foil shows a major scattering peak at $\sim 2.0 \AA$ at reduced distances, which describes the $\mathrm{Ni}-\mathrm{Ni}$ bond of metallic $\mathrm{Ni}$. The EXAFS spectrum of $\mathrm{Ni}-\mathrm{N} / \mathrm{C}$ exhibits a Ni-N scattering peak at $\sim 1.5 \AA$ at reduced distances without the presence of an $\mathrm{Ni}-\mathrm{Ni}$ scattering peak, from which the isolation of $\mathrm{Ni}$ atoms bound to the $\mathrm{N}$-doped carbon support can be concluded.

The Ni 2p X-ray photoelectron spectroscopy (XPS) of Ni-N/C shows a peak around $855 \mathrm{eV}$ (Fig. 1d), corresponding to Ni(II) phthalocyanine (NiPc), and indicates the ionic character of $\mathrm{Ni}$ in $\mathrm{Ni}-\mathrm{N} / \mathrm{C}$. X-ray absorption near edge structure (XANES) spectra of $\mathrm{Ni}-$ $\mathrm{N} / \mathrm{C}$ and NiPc also show similar edge positions (Fig. 1e), confirming the similar oxidation state $\left(\mathrm{Ni}^{2+}\right)$. In addition, the pre- and post-edge peaks in XANES spectra display distorted $\mathrm{Ni}-\mathrm{N} / \mathrm{C}$ coordination environments. The peak labeled $A$ is usually attributed to square-planar structures such as NiPc, absent in Ni-N/C. ${ }^{32,36}$ The higher intensity of peak $B$ compared to that of peak $C$ in the XANES spectrum of $\mathrm{Ni}-\mathrm{N} / \mathrm{C}$ can be explained by the distortion of $D_{4 h}$ symmetry, owing to the displacement of the metal centre, ${ }^{37}$ and is potentially induced by high-temperature pyrolysis.

Electrochemical $\mathrm{CCO}_{2} \mathrm{RR}$ reactivity of catalysts. The catalytic properties of $\mathrm{Ni}-\mathrm{N} / \mathrm{C}$ and $\mathrm{cAg}$ for the $\mathrm{CCO}_{2} \mathrm{RR}$ were investigated in a $\mathrm{CO}_{2}-$ absorbed 5 M MEA aqueous solution. The electrocatalytic conversion was performed in an $\mathrm{H}$-cell after purging with $\mathrm{Ar}$ for 10 min to remove unabsorbed $\mathrm{CO}_{2}$ in the MEA solution. $\mathrm{Ni}-\mathrm{N} / \mathrm{C}$ was found to exhibit superior performance compared to cAg both in the $j_{\mathrm{CO}}$ and product selectivity. $\mathrm{Ni}-\mathrm{N} / \mathrm{C}$ has a maximum $j_{\mathrm{co}}$ of $-3.5 \mathrm{~mA} \mathrm{~cm}{ }^{-2}$, three times larger than $\mathrm{cAg}\left(-0.9 \mathrm{~mA} \mathrm{~cm}^{-2}\right.$, Fig. 1f). Furthermore, it 
shows a maximum CO F. E. (63.2\%) of approximately double that of CAg (30.1\%) with suppressed HER selectivity (Fig. $1 \mathrm{~g}$ and Supplementary Fig. 4). Notably, the CO F. E. of Ni-N/C is the highest value ever reported for the $\mathrm{CCO}_{2} \mathrm{RR}$ in $\mathrm{CO}_{2}$-adsorbed pure MEA electrolyte without $\mathrm{CO}_{2}$ flow (Supplementary Table 1). In addition, the on-set potential of Ni-N/C (-0.45 V vs. RHE) is lower than that of cAg $\left(-0.60 \mathrm{~V}\right.$ vs. RHE), which demonstrates the excellent catalytic activity of $\mathrm{Ni}-\mathrm{N} / \mathrm{C}$ for the $\mathrm{CCO}_{2} \mathrm{RR}$ to $\mathrm{CO}$.

To examine the effect of metal centers on SACs, a number of different metal-based SACs were prepared. Mn-, Fe-, Co-, and Cu-based SACs can be obtained by controlling metal precursors during the ion-exchange step (Supplementary Fig. 5). In contrast with $\mathrm{Ni}$, other metal SACs show almost zero $j_{\mathrm{CO}}$ with high $\mathrm{H}_{2}$ selectivity in the $\mathrm{CCO}_{2} \mathrm{RR}$ (Supplementary Fig. 6). On N-doped carbon (N/C) prepared without ion-exchange, the HER only takes place in high overpotential regions. These results demonstrate that the Ni center plays a key role in the selective $\mathrm{CCO}_{2} \mathrm{RR}$ to $\mathrm{CO}$. The changes in the oxidation state and structure of $\mathrm{Ni}-\mathrm{N} / \mathrm{C}$ during the $\mathrm{cCO}_{2} \mathrm{RR}$ were further investigated through an in situ XANES analysis. From the in situ XANES spectra, significant changes in the structure of Ni-N/C during the $\mathrm{CCO}_{2} \mathrm{RR}$ were not observed (Supplementary Fig. 7), illustrating the catalytic importance of the distorted coordination structure of single atom Ni catalyst, which allows for excellent catalytic performance in the $\mathrm{CCO}_{2} \mathrm{RR}$ without electrolyte-modulating additives.

Practical applicability test using a zero-gap membrane electrode assembly. To evaluate the practical applicability of the $\mathrm{CCO}_{2} \mathrm{RR}$ in high current density, an electrochemical characterization was additionally performed with a zero-gap membrane electrode assembly for the $\mathrm{CCO}_{2} \mathrm{RR}$ in $\mathrm{CO}_{2}$-captured $5 \mathrm{M}$ MEA. BPM was used to drive the regeneration reaction of carbamate $\left(\mathrm{RNHCOO}^{-}+\mathrm{H}^{+} \rightarrow \mathrm{RNH}_{2}+\mathrm{CO}_{2}\right)$, to increase the local concentration of $\mathrm{CO}_{2}$ near the cathode and thus enhance conversion activity (Fig. 2a). At $-50 \mathrm{~mA} \mathrm{~cm}{ }^{-2}$, the CO F. E. of $\mathrm{Ni}-\mathrm{N} / \mathrm{C}$ was $64.9 \%$ (Fig. $2 \mathrm{~b}$ and Supplementary Fig. 8), which is approximately 2.5 times higher than that of cAg (25.5\%), showing a similar trend to $\mathrm{H}$-cell experiments and demonstrating the superior catalytic performance of $\mathrm{Ni}-\mathrm{N} / \mathrm{C}$ for the $\mathrm{cCO}_{2} \mathrm{RR}$ in high current density. When an anion exchange membrane (AEM), the alkaline properties of which favor gas-fed $\mathrm{CO}_{2}$ reduction reaction, is used, significantly lowered $\mathrm{cCO}_{2} \mathrm{RR}$ selectivity has been observed for both Ni-N/C and cAg (Fig. 2b and Supplementary Fig. 8). This could be because AEM is inferior to proton transfer toward the cathode side. From these results, we propose that building a high concentration of liberated $\mathrm{CO}_{2}$ is essential for the $\mathrm{CCO}_{2} \mathrm{RR}$ at high current density of membrane electrode assembly, consistent with previous reports in bicarbonate solutions. ${ }^{18}$ The activity difference in the usage of BPM with AEM provides information on the initial stage of the reaction pathway of $\mathrm{CCO}_{2} \mathrm{RR}$, which will be discussed in the following section.

The $\mathrm{CCO}_{2} \mathrm{RR}$ was then performed in $5 \mathrm{M}$ MEA using $\mathrm{Ni}-\mathrm{N} / \mathrm{C}$ in the membrane electrode assembly with chronopotentiometry at $-50 \mathrm{~mA}$ $\mathrm{cm}^{-2}$ for $10 \mathrm{~h}$. Since the reaction was carried out under $\mathrm{Ar}$, the chemical equilibrium of adsorption/desorption of $\mathrm{CO}_{2}$ in $\mathrm{MEA}$ (Equation (2)) continuously moves to favor desorption of $\mathrm{CO}_{2}$. Hence, the number of carbamate anions and the desorption rate of $\mathrm{CO}_{2}$ were gradually decreased over time, which caused a progressive drop in the CO F. E. after $10 \mathrm{~h}$ (Supplementary Fig. 9). Nevertheless, after the MEA solution was refreshed by $\mathrm{CO}_{2}$ adsorption, the $\mathrm{CO} F$. E. was recovered to $\sim 50 \%$ under Ar conditions. This result demonstrates stable $\mathrm{Ni}-\mathrm{N} / \mathrm{C}$ catalyst operation for the $\mathrm{CCO}_{2} \mathrm{RR}$, and the reduction in $\mathrm{CO}$ selectivity is caused by the diminished amount of adsorbed $\mathrm{CO}_{2}$ in the capturing medium. An important point to note here is the stability of the capturing media. To identify electrochemical degradation or modification of MEA, analysis of the MEA solution before and after the stability test was carried out by ${ }^{1} \mathrm{H}$ nuclear magnetic resonance (NMR) spectroscopy (Supplementary Fig. 10). ${ }^{38}$ No additional ${ }^{1} \mathrm{H}$ NMR peaks were observed after the stability test, indicating the stable operation of MEA during the $\mathrm{CCO}_{2} \mathrm{RR}$ without electrochemical modifications. This result demonstrates that the $\mathrm{CCO}_{2} \mathrm{RR}$ is a promising catalytic system that could even resolve the degradation problems of capturing media in conventional CCUS processes.

Reaction pathway of the $\mathrm{CCO}_{2} \mathrm{RR}$. Next, we designed experiments to understand the pathways of the $\mathrm{CCO}_{2} \mathrm{RR}$ and investigate the effects of different catalysts. First, two scenarios can be considered at the initial stage: i) the active site of the catalyst directly attacks the carbamate anion, or ii) $\mathrm{CO}_{2}$ is released from the MEA followed by electrocatalytic conversion by similar pathways to conventional $\mathrm{CO}_{2} \mathrm{RR}$ (Fig. 3a). A combination of these two scenarios is also possible. Sargent et al. argued for the direct reduction of the $\mathrm{MEA}^{-} \mathrm{CO}_{2}$ adduct (carbamate) through the detection of the ethanolammonium cation on the electrode surface using in situ surface-enhanced Raman spectroscopy, ${ }^{26}$ whereas Goetheer et al. considered the liberated $\mathrm{CO}_{2}$ to be the reactant in temperature-controlled experiments. ${ }^{27}$ In conventional $\mathrm{CO}_{2} \mathrm{RR}$-to- $\mathrm{CO}$, the reaction is initiated by electron injection into $\mathrm{CO}_{2}$, resulting in the unstable $\mathrm{CO}_{2}{ }^{-}$intermediate, which is typically regarded as the rate-determining step (RDS). ${ }^{39,40}$ The stabilization of this intermediate on the catalyst surface is the key to facilitating the $\mathrm{CO}_{2} \mathrm{RR}$. In the $\mathrm{CCO}_{2} \mathrm{RR}$, if the direct reduction of carbamate takes place in the initial stage of the reaction as in scenario (i) and the electron transfer step to carbamate is the RDS of the reaction, the CO production reaction rate with respect to carbamate 
concentration could help identify the initial stage. Thus, in $\mathrm{CO}_{2}$-absorbed 1-5 M MEA solutions, the electrochemical conversion rate of captured $\mathrm{CO}_{2}$ was measured with both $\mathrm{Ni}-\mathrm{N} / \mathrm{C}$ and $\mathrm{cAg}$. The carbamate concentration of the respective MEA solution was determined by quantitative analysis of NMR data (Supplementary Fig. 11) using internal standards. The $j_{\mathrm{CO}}$ for both catalysts is not significantly affected by the concentration of carbamate (Supplementary Fig. 12). Hence, the reaction is considered zeroth-order with respect to carbamate (Fig. 3b), i.e., the reaction rate is independent of the concentration of carbamate for both catalysts. From these results, we speculated that the reactant was in fact the released $\mathrm{CO}_{2}$ from carbamate rather than the carbamate itself.

To regulate the amount of $\mathrm{CO}_{2}$ released in the $\mathrm{H}$-cell, the reaction temperature was controlled. Since the regeneration reaction is endothermic, ${ }^{41}$ the rate of the reaction can be accelerated by increasing the reaction temperature. As the reaction temperature is increased from $5^{\circ} \mathrm{C}$ to $40^{\circ} \mathrm{C}$, the limiting current density (jim. $)$ increases for both catalysts $\left(\mathrm{Ni}-\mathrm{N} / \mathrm{C}:-0.52 \mathrm{~mA} \mathrm{~cm}^{-2}\left(5^{\circ} \mathrm{C}\right) \rightarrow-1.85 \mathrm{~mA}\right.$ $\mathrm{cm}^{-2}(\mathrm{RT}) \rightarrow-3.5 \mathrm{~mA} \mathrm{~cm}^{-2}\left(40^{\circ} \mathrm{C}\right) ; \mathrm{cAg:} 0\left(5^{\circ} \mathrm{C}\right) \rightarrow-0.39 \mathrm{~mA} \mathrm{~cm}{ }^{-2}(\mathrm{RT}) \rightarrow-0.91 \mathrm{~mA} \mathrm{~cm}^{-2}\left(40^{\circ} \mathrm{C}\right)$, Figs. $3 \mathrm{c}$ and d). If the direct reduction of carbamate occurs in the $\mathrm{CCO}_{2} \mathrm{RR}$, the mass transport limit in such low current density is difficult to detect. Furthermore, the amount of carbamate in the electrolyte is reduced as the reaction temperature is increased, and thus even if the $j_{\text {limm. }}$ originates from the

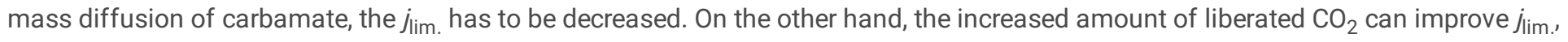
solidifying the proposition of liberated $\mathrm{CO}_{2}$ being the reactant. The sharp increase in reaction rate by the BPM being used in the membrane electrode assembly experiment is consistent with this scenario. It should be noted that the decrease in $j_{\text {lim. }}$ at $60{ }^{\circ} \mathrm{C}$ may originate from the drop in $\mathrm{CO}$ selectivity due to $\mathrm{H}_{2}$ being rapidly generated at high temperatures (Supplementary Fig. 13). Therefore, for the effective electrochemical conversion of captured $\mathrm{CO}_{2}$, the optimal temperature should be found, which involves the trade-off between the amount of liberated $\mathrm{CO}_{2}$ and the reaction rate of HER.

From the experimental results discussed, it can be concluded that the superior performance of $\mathrm{Ni}-\mathrm{N} / \mathrm{C}$ cannot be attributed to the different initial reactions of $\mathrm{cAg}$ and $\mathrm{Ni}-\mathrm{N} / \mathrm{C}$ for the $\mathrm{CCO}_{2} \mathrm{RR}$. The $\mathrm{CCO}_{2} \mathrm{RR}$ pathway appears to be comparable to the conventional $\mathrm{CO}_{2} \mathrm{RR}$, but with a reduced concentration of $\mathrm{CO}_{2}$ in the $\mathrm{CCO}_{2} \mathrm{RR}$. Thus, the high performance of $\mathrm{Ni}-\mathrm{N} / \mathrm{C}$ must originate from the high tolerance of low $\mathrm{CO}_{2}$ concentrations in the $\mathrm{CO}_{2} \mathrm{RR}$ because of its superior $\mathrm{CO}_{2} \mathrm{RR}$ intrinsic activity and high activation energy for the $\mathrm{HER}$, as we previously reported with low-concentration $\mathrm{CO}_{2}$ gas experiments. ${ }^{33}$

Universal reactivity of $\mathrm{Ni}-\mathrm{N} / \mathrm{C}$ for the $\mathrm{CCO}_{2} \mathrm{RR}$. Subsequently, we investigate how $\mathrm{Ni}-\mathrm{N} / \mathrm{C}$ exhibits high reactivity in the presence of bulky ammonium cations for the $\mathrm{CCO}_{2} \mathrm{RR}$. In order to stabilize the $\mathrm{CO}_{2}{ }^{-}$intermediate in the $\mathrm{CO}_{2} \mathrm{RR}$, cations with high surface charge density on the cathode are essential. ${ }^{29}$ Thus, a smaller effective size of alkali metal cation, which creates a higher surface charge density on the cathode, is beneficial to the performance of the $\mathrm{CO}_{2} \mathrm{RR}^{42-47}$ However, amine-based capturing media inevitably generate bulky ammonium cations in the adsorption of $\mathrm{CO}_{2}$, which hampers the stabilization of the $\mathrm{CO}_{2}{ }^{-}$intermediate. However, the effect of bulky cations in the $\mathrm{CCO}_{2} \mathrm{RR}$ has not yet been investigated. To understand the effects of bulky cations, we carried out the $\mathrm{CCO}_{2} \mathrm{RR}$ in systems wherein the bulkiness of the capturing molecule can be controlled. The electrocatalytic performances were examined in six different $\mathrm{CO}_{2}$ capturing media (1 M of potassium bicarbonate, MEA, 3-amino-1-propanol, 2-(methylamino)ethanol, 2-amino-2-methyl-1propanol, and diethanolamine), (Figs. $4 a-4 f$ and Supplementary Fig. 14). The effect of the properties of absorbents on activity trends is also discussed below, with the aim of gaining insights into the activity for the $\mathrm{cCO}_{2} \mathrm{RR}$ (Figs. $4 \mathrm{~g}$ and $\mathrm{h}$ ).

Both $j_{\mathrm{CO}}$ and CO F. E. were found to decrease with increasing bulkiness of capturing media for both $\mathrm{Ni}-\mathrm{N} / \mathrm{C}$ and cAg. One noticeable difference between $\mathrm{Ni}-\mathrm{N} / \mathrm{C}$ and cAg was activity sensitivity depending on cation type. The bulkiness of the cation has a significant impact on cAg, showing a dramatic loss in $j_{\mathrm{CO}}$ as the effective size of the cation increases. The $j_{\mathrm{CO}}$ of cAg fell as low as zero in diethanolamine, a secondary amine (Fig. 4h). In contrast, the $j_{\mathrm{CO}}$ of Ni-N/C is less affected by the effective cation size (Fig. 4g), and the CO F. E. of $\mathrm{Ni}-\mathrm{N} / \mathrm{C}$ was maintained at $~ 50 \%$, irrespective of the electrolyte type (Figs. 4a-4f). From these results, we hypothesized that the marginal cation effect is manifested on $\mathrm{Ni}-\mathrm{N} / \mathrm{C}$, and the weak cation sensitivity allows the selective $\mathrm{CCO}_{2} \mathrm{RR}$ in universal absorbent media. We note, however, that the different types of amine electrolytes not only change the size of the cation but also alter the amount of desorbed $\mathrm{CO}_{2}$ and viscosity of the solvent, which can render the decoupling of the cation effect difficult.

Weak cation sensitivity of $\mathrm{Ni}-\mathrm{N} / \mathrm{C}$ for the $\mathrm{CO}_{2} \mathrm{RR}$. To exclusively identify the difference in cation sensitivity of catalysts, we measured the activity and selectivity of the $\mathrm{CO}_{2} \mathrm{RR}$ in $\mathrm{CO}_{2}$-saturated $0.05 \mathrm{M}$ carbonate electrolytes containing different alkali metal cations ( $\mathrm{Li}^{+}$, $\mathrm{Na}^{+}, \mathrm{K}^{+}$, and $\mathrm{Cs}^{+}$). Similar to the amine solutions, the $j_{\mathrm{CO}}$ of $\mathrm{Ni}-\mathrm{N} / \mathrm{C}$ and cAg decreased as the effective cation radius increased from 
$\mathrm{Cs}^{+}$to $\mathrm{Li}^{+}$(Figs. 5a and b), but the cation sensitivity was clearly different in $\mathrm{Ni}-\mathrm{N} / \mathrm{C}$ compared to cAg. The maximum CO F. E. of Ni-N/C ( $100 \%$ ) was maintained irrespective of the electrolyte used, whereas that of cAg was reduced to $\sim 85 \%$ in $0.05 \mathrm{M} \mathrm{Na}_{2} \mathrm{CO}_{3}$ and $\sim 75 \%$ in $0.05 \mathrm{M} \mathrm{Li}_{2} \mathrm{CO}_{3}$ (Figs. $5 \mathrm{c}$ and d). The normalized $j_{\mathrm{CO}}$ by $j_{\mathrm{CO}}$ in the presence of $\mathrm{Cs}^{+}$is higher in $\mathrm{Ni}-\mathrm{N} / \mathrm{C}$ than that in cAg, and the slope of the normalized value with respect to the effective cation radius of $\mathrm{Ni}-\mathrm{N} / \mathrm{C}$ is less steep than that of cAg (Fig. $5 \mathrm{e}$ ). These results demonstrate that the cation sensitivity can be varied depending on the type of catalyst and that $\mathrm{Ni}-\mathrm{N} / \mathrm{C}$ shows weaker cation sensitivity compared with cAg.

The accumulated cation density at the EDL can be determined by the size of the cation, the applied potential, and the PZC of the electrode. ${ }^{48}$ The weak cation sensitivity of $\mathrm{Ni}-\mathrm{N} / \mathrm{C}$ may arise from its relatively high PZC. In the presence of any cation, Ni-N/C exhibits a $~ 0.6$ V higher PZC compared to cAg (Supplementary Fig. 15). This positive-shifted PZC can create an increased surface charge density for the same applied potential in the reduction reaction, which in turn may be prone to stabilizing the $\mathrm{CO}_{2}{ }^{-}$intermediate, thus mitigating the cation effect. The positive-shifted PZC of Ni-N/C, therefore, allows for the effective accumulation of cations to stabilize the $\mathrm{CO}_{2}{ }^{-}$intermediate, even in the presence of large cations such as $\mathrm{Li}^{+}$or ammonium, without additives. The marginal cation effect on $\mathrm{Ni}-\mathrm{N} / \mathrm{C}$ permits the selective $\mathrm{CCO}_{2} \mathrm{RR}$ in universal capturing media.

\section{Conclusions}

We have demonstrated that $\mathrm{Ni}-\mathrm{N} / \mathrm{C}$ is an effective catalyst for the direct electroconversion of captured $\mathrm{CO}_{2}$ by amine-based absorbents. Ni-N/C showed $64.9 \%$ of maximum CO F. E. at $-50 \mathrm{~mA} \mathrm{~cm}{ }^{-2}$ for the $\mathrm{CCO}_{2} \mathrm{RR}$, making it the highest value ever reported in $\mathrm{CO}_{2}$-captured MEA solution without $\mathrm{CO}_{2}$ flow and additives. To understand the initial stage of the reaction in the capture media, the $\mathrm{CO}$ productivity was investigated by controlling the carbamate concentration, reaction temperature, and type of membrane in the membrane electrode assembly, which provided evidence for liberated $\mathrm{CO}_{2}$ being the reactant in the $\mathrm{CCO}_{2} \mathrm{RR}$. We have also proposed that $\mathrm{Ni}-\mathrm{N} / \mathrm{C}$ is a universal catalyst to maintain high $\mathrm{CO}$ selectivity in various amine-based absorbent for the $\mathrm{CCO}_{2} \mathrm{RR}$. By controlling the size of cations in carbonate electrolytes, we further demonstrate that the $\mathrm{CO}_{2} \mathrm{RR}$ performance of $\mathrm{Ni}-\mathrm{N} / \mathrm{C}$ is less affected by cation size compared to that of cAg. The weak cation sensitivity allows for the maintenance of a CO F. E of Ni-N/C of up to $50 \%$, even in bulkier capturing media. This distinguishes it from commercial Ag, where it was found that the CO F.E. gradually decreased to $0 \%$ with increasing amine bulkiness. In addition to high suppressing ability of HER, the weak cation effect of Ni-N/C may be attributed to the high PZC of Ni-N/C, which can maintain a high surface charge density, irrespective of the size and bulkiness of cations. We envisage that these results will provide important catalytic insights into integrated $\mathrm{CO}_{2}$ capture and electroconversion systems and the preparation of catalysts for them.

\section{Methods}

Chemicals. Zinc nitrate hexahydrate $\left.\left(\mathrm{Zn}_{\left(\mathrm{NO}_{3}\right.}\right)_{2} \cdot 6 \mathrm{H}_{2} \mathrm{O}, \geq 99.0 \%\right)$, 2-methylimdazole (MelM, 99\%), manganese nitrate hydrate $\left(\mathrm{Mn}\left(\mathrm{NO}_{3}\right)_{2} \cdot \times \mathrm{H}_{2} \mathrm{O}, 99.99 \%\right)$, iron chloride $\left(\mathrm{FeCl}_{2}, 98 \%\right)$, copper nitrate trihydrate $\left(\mathrm{Cu}\left(\mathrm{NO}_{3}\right)_{2} \cdot 3 \mathrm{H}_{2} \mathrm{O}, 99-104 \%\right), 5$ wt.\% Nafion, ethanolamine ( $\geq 99.0 \%)$, diethanolamine ( $\geq 99.0 \%)$, potassium bicarbonate ( $\geq 99.7 \%)$, 3-amino-1-propanol (99\%), 2-(methylamino)ethanol ( $\geq 98 \%$ ), and 2-amino-2-methyl-1-propanol ( $\geq 95 \%)$ were purchased from Sigma-Aldrich. Methanol (99.5\%), n-hexane (95\%), ethanol (94.5\%) and 2-propanol (99.8\%) were purchased from Samchun Chemicals (Korea). Nickel nitrate hexahydrate $\left(\mathrm{Ni}\left(\mathrm{NO}_{3}\right)_{2} \cdot 6 \mathrm{H}_{2} \mathrm{O}\right.$, crystalline/certified) was purchased from Fisher Chemicals. Cobalt nitrate hexahydrate $\left(\mathrm{Co}\left(\mathrm{NO}_{3}\right) \cdot 6 \mathrm{H}_{2} \mathrm{O}, 99-102 \%\right)$, carbon paper (TGP-H-120 20\%WP, Toray), commercial Ag (20-40 nm, 99.9\%), and $\mathrm{IrO}_{2}$ (Premion ${ }^{\circledR}, 99.99 \%$ ) were purchased from Alfa Aesar. AEM (Sustanion X37-50 Grade RT) for the membrane electrode assembly was purchased by Dioxide Materials. BPM (Fumasep FBM-PK, FuMA-Tech), PtTi mesh, and gas diffusion layers (GDL, Sigracet 39 BB, SGL Carbon) were purchased from Fuel Cell Store. All chemicals were utilized without further purification.

Synthesis of ZIF-8. ZIF-8 was synthesized by a previously-reported method, with some modifications. ${ }^{32}$ After $\mathrm{Zn}\left(\mathrm{NO}_{3}\right) \cdot 6 \mathrm{H}_{2} \mathrm{O}(2.93 \mathrm{~g})$ and MelM (6.49 g) were each separately dissolved completely in methanol $(100 \mathrm{~mL})$, the solutions were mixed by magnetic stirring at room temperature (RT) for $24 \mathrm{~h}$ to induce the self-assembly between metal nodes and organic linkers. The resulting suspension was vacuum-filtered and washed several times with methanol. The resulting white powder was then dried overnight at $80^{\circ} \mathrm{C}$.

Synthesis of ZIF-8-derived M-N/C catalysts. To produce ZIF-8-derived single atom Ni-N/C catalysts, Zn was replaced by Ni in an ionexchange reaction. Prior to the ion-exchange, ZIF-8 (0.100 g) was dispersed in hexane $(10 \mathrm{~mL})$ by sonication for $15 \mathrm{~min}$.

Page 6/15 
$\mathrm{Ni}\left(\mathrm{NO}_{3}\right) \cdot 6 \mathrm{H}_{2} \mathrm{O}$ solution $(0.6 \mathrm{M}, 25 \mu \mathrm{L})$ was added dropwise to the ZIF-8-dispersed hexane suspension under sonication. The ionexchange reaction was carried out under vigorous stirring $(1000 \mathrm{rpm})$ at RT for $3 \mathrm{~h}$. The ion-exchanged ZIF-8 was separated from hexane by centrifugation ( $8000 \mathrm{rpm}$ for $10 \mathrm{~min}$ ). The resulting powder was dried overnight at $80^{\circ} \mathrm{C}$. The dried powder was carbonized at $1000{ }^{\circ} \mathrm{C}$ at a ramping rate of $4.9^{\circ} \mathrm{C} \mathrm{min}^{-1}$ for $2 \mathrm{~h}$ under Ar flow. To prepare single atom Mn, Fe, Co, or Cu catalysts, $\mathrm{Ni}\left(\mathrm{NO}_{3}\right) \cdot 6 \mathrm{H}_{2} \mathrm{O}$ is replaced by $\mathrm{Mn}\left(\mathrm{NO}_{3}\right)_{2} \cdot \mathrm{xH}_{2} \mathrm{O}, \mathrm{FeCl}_{2}, \mathrm{Co}\left(\mathrm{NO}_{3}\right)_{2} \cdot 6 \mathrm{H}_{2} \mathrm{O}$, and $\mathrm{Cu}\left(\mathrm{NO}_{3}\right)_{2} \cdot 3 \mathrm{H}_{2} \mathrm{O}$, respectively, in the ion-exchange step.

Material characterizations. SEM images were captured using an Inspect F instrument (FEI). The TEM, HAADF-STEM, and energy dispersive spectroscopy images were obtained by TECNAI F20 G² (FEI), Titan 80-300 (FEI) equipped with a double-sided spherical aberration (Cs) corrector, and Talos F200X (FEI), respectively. XPS spectra were obtained using a Nexsa (Thermo Fisher Scientific) with a monochromated Al-Ka source. The X-ray absorption fine structure (XAFS) was analyzed at the 1D KIST-PAL beamline of the Pohang Light Source (PLS-II) in a $3.0 \mathrm{GeV}$ storage ring with a ring current of $250 \mathrm{~mA}$. The X-ray beam was monochromated by a Si(111) double crystal. The XAFS spectra were collected in transmission and fluorescence modes. An electrochemical in situ XAFS analysis was performed using the modified $\mathrm{H}$-cell. The catalyst-loaded $\left(1 \mathrm{mg} \mathrm{cm}^{-1}\right)$ carbon paper strip was attached to the window of the $\mathrm{H}$-cell and sealed with Kapton tape. $\mathrm{An} \mathrm{Ag} / \mathrm{AgCl}(3 \mathrm{M} \mathrm{KCl}$ filling solution) reference electrode and Pt plate counter electrode were used to form the three-electrode system. The XAFS spectra were obtained in $\mathrm{CO}_{2}$-adsorbed MEA (5 M) solution after applying a fixed potential for 10 min from the fluorescence mode with Ar gas purging. The post-treatment of the obtained spectra was performed by Demeter software.

Electrochemical characterizations. Electrochemical characterizations were performed using an IviumStat electrochemical analyzer in a gas-tight $\mathrm{H}$-cell using a three-electrode system. To prepare the working electrodes, catalysts were deposited onto carbon paper (area: $0.5 \mathrm{~cm}^{2}$ ) using $500 \mu \mathrm{L}$ of catalaminyst ink spray. The catalyst ink was prepared by dispersing catalysts ( $3 \mathrm{mg}$ ) in a mixture of 2propanol $(3 \mathrm{~mL})$ and $5 \mathrm{wt}$.\% Nafion solution $(30 \mu \mathrm{L})$ under sonication for $30 \mathrm{~min}$. $\mathrm{Ag} / \mathrm{AgCl}$ and Pt plate electrodes were used for the reference and counter electrodes, respectively. To separate the catholyte and anolyte, an AEM (Selemion AMV) was used. $\mathrm{KHCO}_{3}(0.5$ M) was used as an anolyte. As catholytes, $\operatorname{Ar}(99.999 \%)$-saturated monoethanolamine (1-5 M), $\mathrm{KHCO}_{3}(1 \mathrm{M}), 3$-amino-1-propanol (1 M), 2-(methylamino)ethanol (1 M), 2-amino-2-methyl-1-propanol (1 M), and diethanolamine (1 M) were used after $\mathrm{CO}_{2}$-adsorption by $\mathrm{CO}_{2}(99.99 \%)$ flow for at least $1 \mathrm{~h}$. The activity and selectivity of catalysts for the $\mathrm{CO}_{2} \mathrm{RR}$ were measured by chronoamperometry, by applying fixed potentials under Ar flow, at a flow rate of $100 \mathrm{sccm}$. Prior to applying each potential, $\mathrm{CO}_{2}$-capture and Ar-saturation steps were sequentially carried out for 10 min each. $i R$-compensation was conducted for each potential by determining a series resistance from electrochemical impedance spectroscopy (EIS). Potential conversion into the reversible hydrogen electrode (RHE) scale was performed using Equation (3):

$E(v s . R H E)=E(v s . A g / A g C l)+0.210 \mathrm{~V}+0.059 \mathrm{~V} \times p H$

All electrochemical characterizations were carried out in a water bath set to $40^{\circ} \mathrm{C}$, except in temperature-controlled experiments. Cation sensitivity was investigated in $\mathrm{CO}_{2}$-saturated $0.05 \mathrm{M} \mathrm{M}_{2} \mathrm{CO}_{3}$ electrolytes ( $\mathrm{M}$ : $\mathrm{Li}, \mathrm{Na}$, $\mathrm{K}$, and $\mathrm{Cs}$ ) at RT. Differential capacitance was measured to obtain the PZC of catalysts in $0.05 \mathrm{M} \mathrm{M}_{2} \mathrm{CO}_{3}$ electrolyte with a frequency of $100 \mathrm{mHz}$ and a $10 \mathrm{mV}$ potential amplitude. The capacitance, $C$, was calculated by Equation (4),

$$
C=-\left(\omega Z_{I m}\right)^{-1}
$$

where $\omega$ denotes the frequency and $Z_{I m}$ denotes the imaginary part of the Nyquist plot of EIS.

Membrane electrode assembly electrolyzer experiment. The practicability test of the direct electrochemical conversion of captured- $\mathrm{CO}_{2}$ was performed using a custom-designed membrane electrode assembly electrolyzer with a zero-gap configuration (Supplementary Fig. 16). The anode was prepared by spraying $1.2 \mathrm{~mL}$ of $\mathrm{IrO}_{2}$ ink on quadruply stacked sheets of PtTi mesh. The $\mathrm{IrO}_{2}$ ink was prepared by dispersing $\mathrm{IrO}_{2}(0.300 \mathrm{~g})$ in a mixture of 2-propanol $(10 \mathrm{~mL})$ and $5 \mathrm{wt}$.\% Nafion solution $(1.2 \mathrm{~mL})$ under sonication for $30 \mathrm{~min}$. The cathode was assembled by spraying a catalyst ink on a GDL (area: $5 \mathrm{~cm}^{2}$ ). The catalyst ink was prepared by mixing catalyst (9 mg), 2propanol $(1.5 \mathrm{~mL})$, and $5 \mathrm{wt} . \%$ Nafion solution $(90 \mu \mathrm{L})$ under sonication for $30 \mathrm{~min}$. The cathode catalyst layer, membrane, and anode were stacked with a zero-gap. For the membrane, either BPM or AEM were applied. $\mathrm{KHCO}_{3}(0.5 \mathrm{M})$ and MEA (5 M) aqueous electrolytes were used as the anolyte and catholyte, respectively. The electrolytes were circulated around a flow channel of bipolar plates using a peristaltic pump at a rotating speed of $16 \mathrm{rpm}$. The catalytic properties were evaluated by chronopotentiometry under Ar flow at a flow

Page $7 / 15$ 
rate of $100 \mathrm{sccm}$, after the $\mathrm{CO}_{2}$-capture and Ar-saturation steps were sequentially carried out over 10 min. The temperature of the membrane electrode assembly electrolyzer was set to $40^{\circ} \mathrm{C}$ by temperature controllers connected to the bipolar plates.

Gaseous product analysis. The gaseous products were quantified at fixed potentials or currents using gas chromatography (GC, Agilent 7890B). The gas flow outlet in the H-cell or the membrane electrode assembly electrolyzer was directly connected to the GC inlet. The gaseous products were injected using a six-port valve system. Ar (99.999\%) was used as the carrier gas, and a Carboxen 1000 packed column (Supelco) was used. The number of gaseous products was quantified using a thermal conductivity detector or a flame ionization detector equipped with a methanizer depending on the concentration of CO. The F.E. of gaseous products was calculated by Equation (5):

$$
\text { F. } \mathrm{E}_{\mathrm{H}_{2} \text { orco }}=i_{\mathrm{H}_{2} \text { orco }} /\left(i_{\mathrm{H}_{2}}+i_{\mathrm{CO}}\right) \times 100
$$

where $i_{\mathrm{H}_{2}}$ and $i_{\mathrm{CO}}$ indicate partial current of $\mathrm{H}_{2}$ and $\mathrm{CO}$, respectively. The $i_{\mathrm{H}_{2} \text { orco }}$ was obtained using Equation (6):

$$
i_{\mathrm{H}_{2} \text { orco }}=C_{\mathrm{H}_{2} \text { orco }} \times Q \times \frac{2 F P_{0}}{R T}
$$

where $C_{\mathrm{H}_{2}}$ or co, $Q, F, P_{0}, R$, and $T$ indicate the volume concentration of $\mathrm{H}_{2}$ or $\mathrm{CO}$, flow rate of gas, atmospheric pressure, ideal gas constant, and temperature, respectively.

Quantitative analysis of ${ }^{1} \mathrm{H}$ NMR. The concentration of carbamate was quantified by ${ }^{1} \mathrm{H}$ NMR (Varian 500 , Agilent). To prepare a solution for NMR measurement, the MEA solutions (1-5 M) were diluted by mixing $5 \mu \mathrm{L}$ of MEA solution with $495 \mu \mathrm{L}$ of deionized water. Subsequently, $450 \mu \mathrm{L}$ of the diluted solutions was added to $50 \mu \mathrm{L}$ of $\mathrm{D}_{2} \mathrm{O}$ in which $50 \mathrm{mmol}$ of dimethyl sulfoxide (DMSO) was dissolved. The concentration of carbamate was determined by comparison with the integrated peak area between the carbamate and the DMSO internal standard.

Estimation of effective cation radius. The effective cation radius was estimated with reference to previous reports. ${ }^{29,49,50}$ The effective cation radii of $\mathrm{CO}_{2}$-adsorbed MEA, 3-amino-1-propanol, 2-amino-2-methyl-1-propanol, and diethanolamine were estimated from the reported effective cation radii of ethylammonium, isopropylammonium, isobutylammonium, diethylammonium, respectively. The effective cation radius of $\mathrm{CO}_{2}$-adsorbed 2-(methylamino)ethanol was estimated by halving the sum of the effective cation radii of dimethylammonium and diethylammonium. ${ }^{49}$ The effective cation radius of $\mathrm{K}^{+}$was estimated by considering the relative effective radius between ethyl ammonium and $\mathrm{K}^{+}$in the previous report. ${ }^{50}$ The effective cation radius of other alkali metal cations $\left(\mathrm{Li}^{+}, \mathrm{Na}^{+}\right.$, and $\mathrm{Cs}^{+}$) was estimated using the relative effective radius between $\mathrm{K}^{+}$and $\mathrm{M}^{+}$in the previous report. ${ }^{29}$

\section{References}

1. Voosen, P. Science 373, 474-475. (2021).

2. IPCC Sixth Assessment Report (Intergovernmental Panel on Climate Change, 2021).

3. The Paris Agreement (United Nations, 2015).

4. CCUS in Clean Energy Transition (International Energy Agency, 2020)

5. Bui. M. et al. Carbon capture and storage (CCS): the way forward. Energy Environ. Sci. 11, 1062-1176 (2018).

6. Rochelle, G. T. Amine scrubbing for $\mathrm{CO}_{2}$ capture. Science 325, 1652-1654 (2009).

7. Keith, D. W., Holmes, G., Angelo, D. St. \& Heidel, K. A process for capturing $\mathrm{CO}_{2}$ from the atmosphere. Joule 2, 1573-1594 (2018).

8. Gao, W. et al. Industrial carbon dioxide capture and utilization: state of the art and future challenges. Energy Environ. Sci. 49, 8584$8686(2020)$.

9. Kar, S., Goeppert, A. \& Prakash, S. K. S. Integrated $\mathrm{CO}_{2}$ capture and conversion to formate and methanol: connecting two threads. Acc. Chem. Res. 52, 2892-2903 (2019).

10. Chi, S. \& Rochelle, G. T. Oxidative degradation of monoethanolamine. Int. Eng. Chem. Res. 41, 4178-4186 (2002).

11. J. Davis \& Rochelle, G. Thermal degradation of monoethanolamine at stripper conditions. Energy Procedia 1, 327-333 (2009). 
12. Renfrew, S. E., Starr, D. E., Strasser, P. Electrochemical approaches toward $\mathrm{CO}_{2}$ capture and concentration. ACS Catal. 10, 1305813074 (2020).

13. Zhang, S., Chen, C., Li, K., Yu, H. \& Li, F. Materials and system design for direct electrochemical $\mathrm{CO}_{2}$ conversion in capture media. J. Mater. Chem. A 9, 18785-18792 (2021).

14. Sullivan, I. et al. Coupling electrochemical $\mathrm{CO}_{2}$ conversion with $\mathrm{CO}_{2}$ capture. Nat. Catal. 4, 952-958 (2021).

15. Gallant, B. M. Nat. Energy 6, 13-14 (2021).

16. Hori, X. \& Suzuki, S. Electrolytic reduction of bicarbonate ion at a mercury electrode. J. Electrochem. Soc. 130, $2387-2390$ (1983).

17. Min, X. \& Kanan, M. W. Pd-catalyzed electrohydrogenation of carbon dioxide to formate: high mass activity at low overpotential and identification of the deactivation pathway. J. Am. Chem. Soc. 137, 4701-4708 (2015).

18. Li, T. et al. Electrolytic conversion of bicarbonate into CO in a flow cell. Joule 3, 1487-1497 (2019).

19. Li, Y. C. et al. $\mathrm{CO}_{2}$ electroreduction from carbonate. ACS Energy Lett. 4, 1427-1431. (2019).

20. Lees, E. W. et al. Electrodes designed for converting bicarbonate into CO. ACS Energy Lett. 5, 2165-2173 (2020).

21. Li, T., Lees, E. W., Zhang, Z. \& Berlinguette, C. P. Conversion of bicarbonate to formate in an electrochemical flow reactor. ACS Energy Lett. 5, 2624-2630 (2020).

22. Fink, A. G. et al. Impact of alkali cation identity on the conversion of $\mathrm{HCO}_{3}{ }^{-}$to $\mathrm{CO}$ in bicarbonate electrolyzers. ChemElectroChem 8 , 2094-2100 (2021).

23. Zhang, Z. et al. Porous metal electrodes enable efficient electrolysis of carbon capture solutions. Energy Environ. Sci. https://doi.org/10.1039/D1EE02608A (2022).

24. Chen, L. et al. Electrochemical reduction of carbon dioxide in a monoethanolamine capture medium. ChemSusChem 10, 41094118 (2017).

25. Abdinejad, M., Mirza, Z., Zhang, X.-A. \& Kraatz, H.-B. Enhanced electrocatalytic activity of primary amines for $\mathrm{CO}_{2}$ reduction using copper electrodes in aqueous solution. ACS Sustainable Chem. Eng. 8, 1715-1720 (2020).

26. Lee, G. et al. Electrochemical upgrade of $\mathrm{CO}_{2}$ from amine capture solution. Nat. Energy 6, 46-53 (2021).

27. Pérez-Gallent, E. Vankani, C., Sánchez-Martínez, C., Anastasopol, A. \& Goetheer, E. Integrating $\mathrm{CO}_{2}$ capture with electrochemical conversion using amine-based capture solvents as electrolytes. Ind. Eng. Chem. Res. 60, 4269-4278 (2021).

28. Salvatore, D. A. et al. Designing anion exchange membranes for $\mathrm{CO}_{2}$ electrolysers. Nat. Energy 6, 339-348 (2021).

29. Ringe, S. et al. Understanding cation effects in electrochemical $\mathrm{CO}_{2}$ reduction. Energy Environ. Sci. 12, 3001-3014 (2019).

30. Vega, F. et al. Carbon dioxide chemistry, capture and oil recovery Ch. 8 (IntechOpen, 2018).

31. Mitchell, S. \& Pérez-Ramírez, J. Single atom catalysis: a decade of stunning progress and the promise for a bright future. Nat. Commun. 11, 4302 (2020).

32. Sa, Y. J. et al. Thermal transformation of molecular $\mathrm{Ni}^{2+}-\mathrm{N}_{4}$ sites for enhanced $\mathrm{CO}_{2}$ electroreduction activity. ACS Catal. 10, 10920-10931 (2020).

33. D. Kim et al. Electrocatalytic reduction of low concentrations of $\mathrm{CO}_{2}$ gas in a membrane electrode assembly electrolyzer. ACS Energy Lett. 6, 3488-3495 (2021).

34. Zhao, C. et al. Ionic exchange of metal-organic frameworks to access single nickel sites for efficient electroreduction of $\mathrm{CO}_{2}$. J. Am. Chem. Soc. 139, 8078-8081 (2017).

35. Wei, S. et al. Direct observation of noble metal nanoparticles transforming to thermally stable single atoms. Nat. Nanotechnol. 13, 856-861 (2018).

36. Gaur, A. et al. XAFS study of copper(II) complexes with square planar and square pyramidal coordination geometries. J. Mol. Struct. 1118, 212-218 (2016).

37. Jia, Q. et al. Experimental observation of redox-induced $\mathrm{Fe}-\mathrm{N}$ switching behavior as a determinant role for oxygen reduction activity. ACS Nano 9, 12496-12505 (2015).

38. Perinu, C. Arstad, B. Jens, K.-J. NMR spectroscopy applied to amine- $\mathrm{CO}_{2}-\mathrm{H}_{2} \mathrm{O}$ systems relevant for post-combustion $\mathrm{CO}_{2}$ capture: A review. Int. J. Greenh. Gas Con. 20, 230-243 (2014). 
39. Cheng, T. Xiao, H. Goddard III, W. A. Reaction mechanisms for the electrochemical reduction of $\mathrm{CO}_{2}$ to $\mathrm{CO}$ and formate on the $\mathrm{Cu}(100)$ surface at $298 \mathrm{~K}$ from quantum mechanics free energy calculations with explicit water. J. Am. Chem. Soc. 138, 1380213805 (2016).

40. Singh, M. R. Goodpaster, J. D. Weber, A. Z. Head-Gordon, M. Bell, A. T. Mechanistic insights into electrochemical reduction of CO 2 over Ag using density functional theory and transport models. Proc. Natl. Acad. Sci. U. S. A. 114, E8812-E8821 (2017).

41. Song, C. Kansha, Y. Ishizuka, M. Fu, Q. Tsutsumi, A. Design of low-cost $\mathrm{CO}_{2}$ capture process based on heat integration technology. Energy Procedia 61, 365-368 (2014).

42. Strmcnik, D. et al. The role of non-covalent interactions in electrocatalytic fuel-cell reactions on platinum. Nat. Chem. 1, 466-472 (2009).

43. Singh, M. R., Kwon, Y., Lum, Y., Ager, J. W. \& Bell, A. T. Hydrolysis of electrolyte cations enhances the electrochemical reduction of $\mathrm{CO}_{2}$ over $\mathrm{Ag}$ and Cu. J. Am. Chem. Soc. 138, 13006-13012 (2016).

44. Chen, L. D., Urushihara, M., Chan, K. \& Nørskov, J. K. Electric field effects in electrochemical $\mathrm{CO}_{2}$ reduction. $A C S$ Catal. 6, 71337139 (2016).

45. Resasco, J. et al. Promoter effects of alkali metal cations on the electrochemical reduction of carbon dioxide. J. Am. Chem. Soc. 139, 11277-11287 (2017).

46. Hussain, G. et al. How cations determine the interfacial potential profile: relevance for the $\mathrm{CO}_{2}$ reduction reaction. Electrochim. Acta 327, 135055 (2019).

47. Monteiro, M. C. O. et al. Absence of $\mathrm{CO}_{2}$ electroreduction on copper, gold and silver electrodes without metal cations in solution. Nat. Catal. 4,654-662 (2021).

48. Shin, S.-J. et al. On the importance of the electric double layer structure in aqueous electrocatalysis. Nat. Commun. 13, 174 (2022).

49. Becker, M., Kluner, T. \& Wark, M. Formation of hybrid $\mathrm{ABX}_{3}$ perovskite compounds for solar cell application: first-rpinciples calculations of effective ionic radii and determination of tolerance factors. Dalton Trans. 46, 3500-3509 (2017).

50. Kour, R. et al. Potential substitutes for replacement of lead in perovskite solar cells: a review. Global Challenges 3, 1900050 (2019).

\section{Declarations}

\section{Acknowledgements}

This work was supported by the Institute for Basic Science (IBS-R006-D1) and also by Creative-Pioneering Researchers Program through Seoul National University. We also acknowledge the valuable discussion with Jong Suk Yoo (University of Seoul) to understand the cation sensitivity of Ni-N/C.

\section{Author contributions}

Y.J.H. supervised the project. Y.J.H. and J.H.K. conceived and designed the experiments and co-wrote the manuscript. J.H.K. conducted synthesis, physicochemical characterisation, and electrochemical analysis with assistance from H.J., W.C., H. Y., E.C.L., D.K., J.K., and S.Y.L.

\section{Competing interests}

The authors declare no competing interests.

\section{Additional information}

Correspondence and requests for materials should be addressed to Yun Jeong Hwang.

\section{Figures}


a
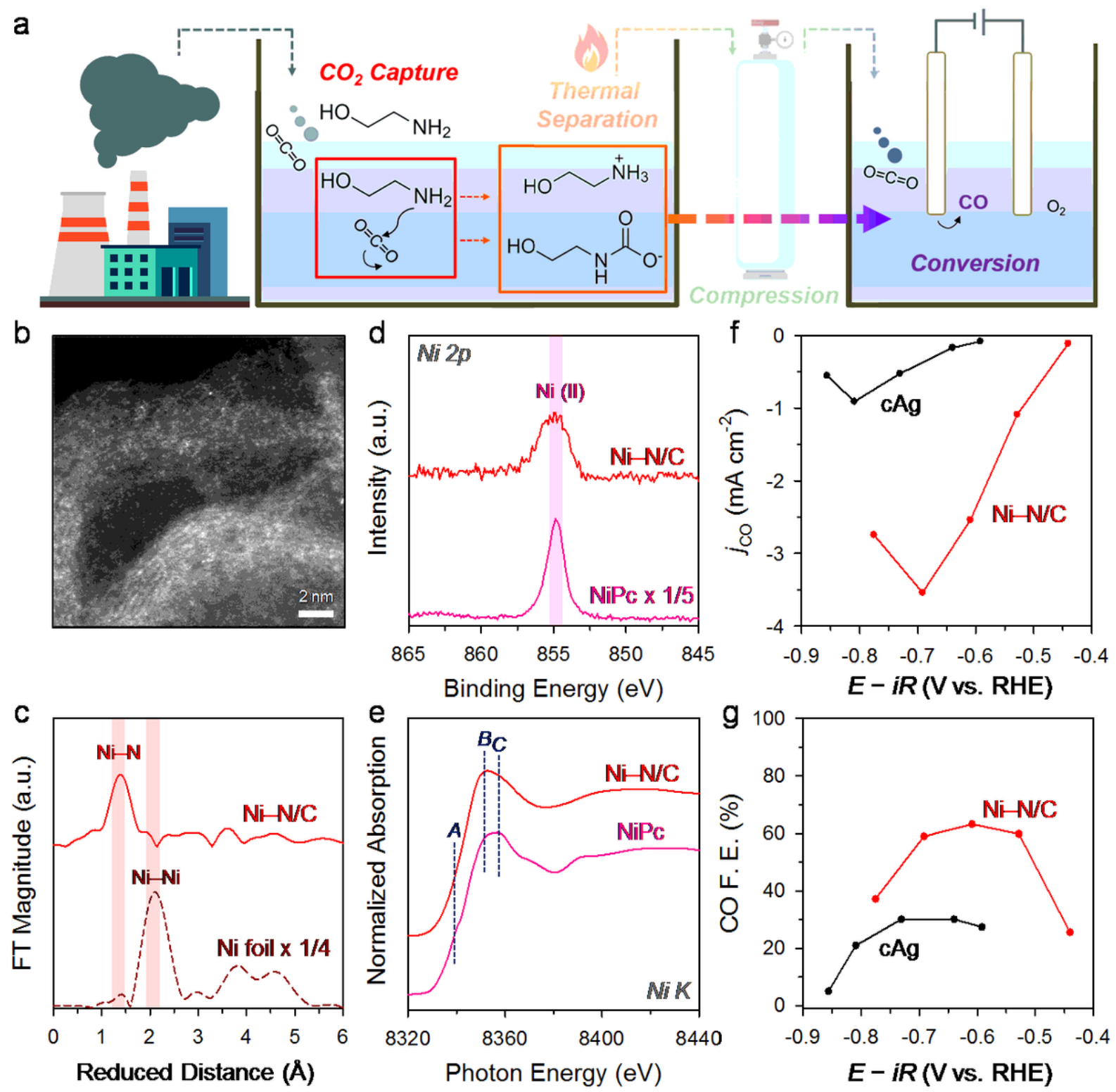

Figure 1

Direct electroconversion of captured $\mathrm{CO}_{2}$ with single atom $\mathrm{Ni}-\mathrm{N} / \mathrm{C}$ catalyst. a, Schematic illustration of direct electroconversion of captured $\mathrm{CO}_{2}$. b, HAADF-STEM images of Ni-N/C. c, Ni K-edge $k^{3}$-weighted EXAFS spectra of Ni-N/C and Ni foil. d,e, Ni $2 p$ XPS spectra (d) and Ni K-edge XANES spectra (e) of Ni-N/C and NiPc. f,g, $j_{\mathrm{CO}}(\mathbf{f})$ and $\mathrm{CO} F$. E. (g) of Ni-N/C and cAg for the $\mathrm{cCO}_{2} \mathrm{RR}$ in $\mathrm{CO}_{2}-$ adsorbed 5 M MEA solution. 
a

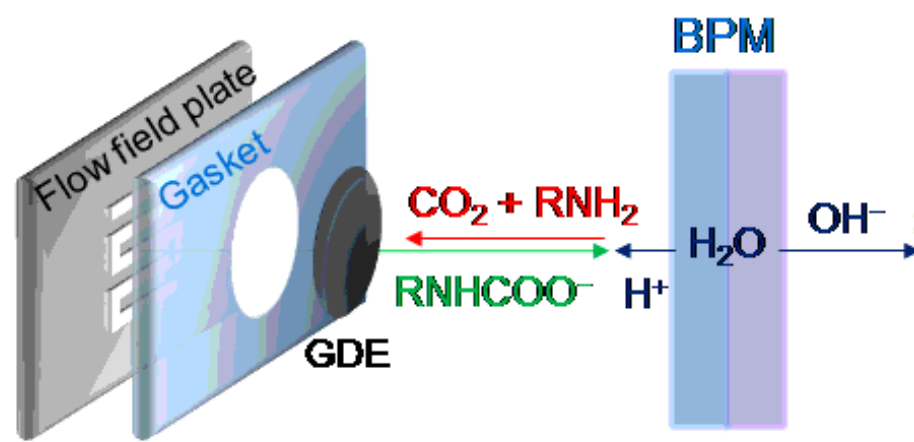

Cathode

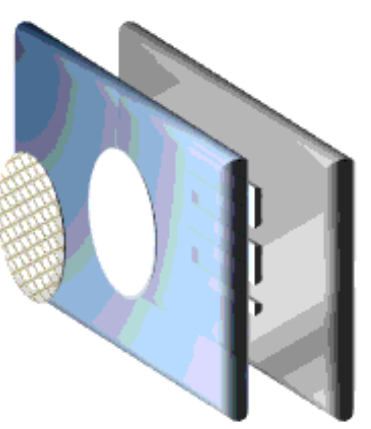

Anode

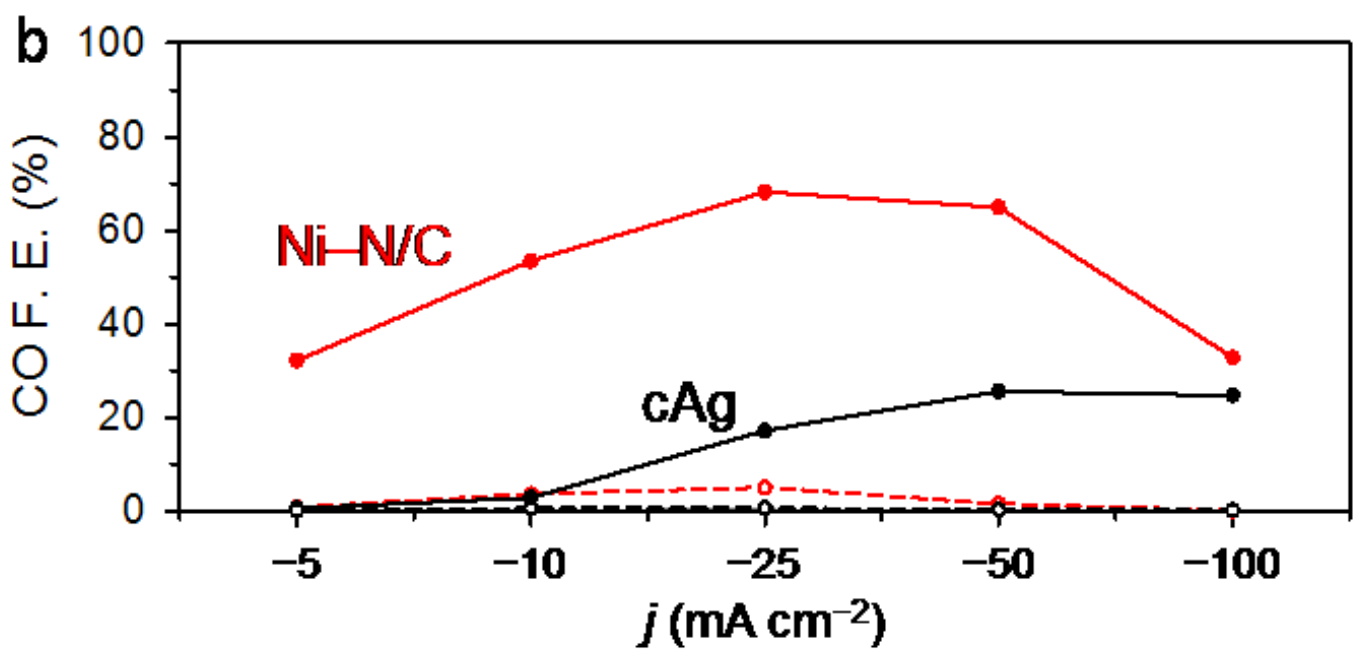

Figure 2

Membrane electrode assembly test for the $\mathrm{CCO}_{2} \mathrm{RR}$. a, Schematic illustration of $\mathrm{CO}_{2}$ regeneration using BPM in the membrane electrode assembly. b, CO F. E. of Ni-N/C and cAg in chronopotentiometry using the membrane electrode assembly. The solid and dashed lines indicate the use of BPM and AEM, respectively. 
a
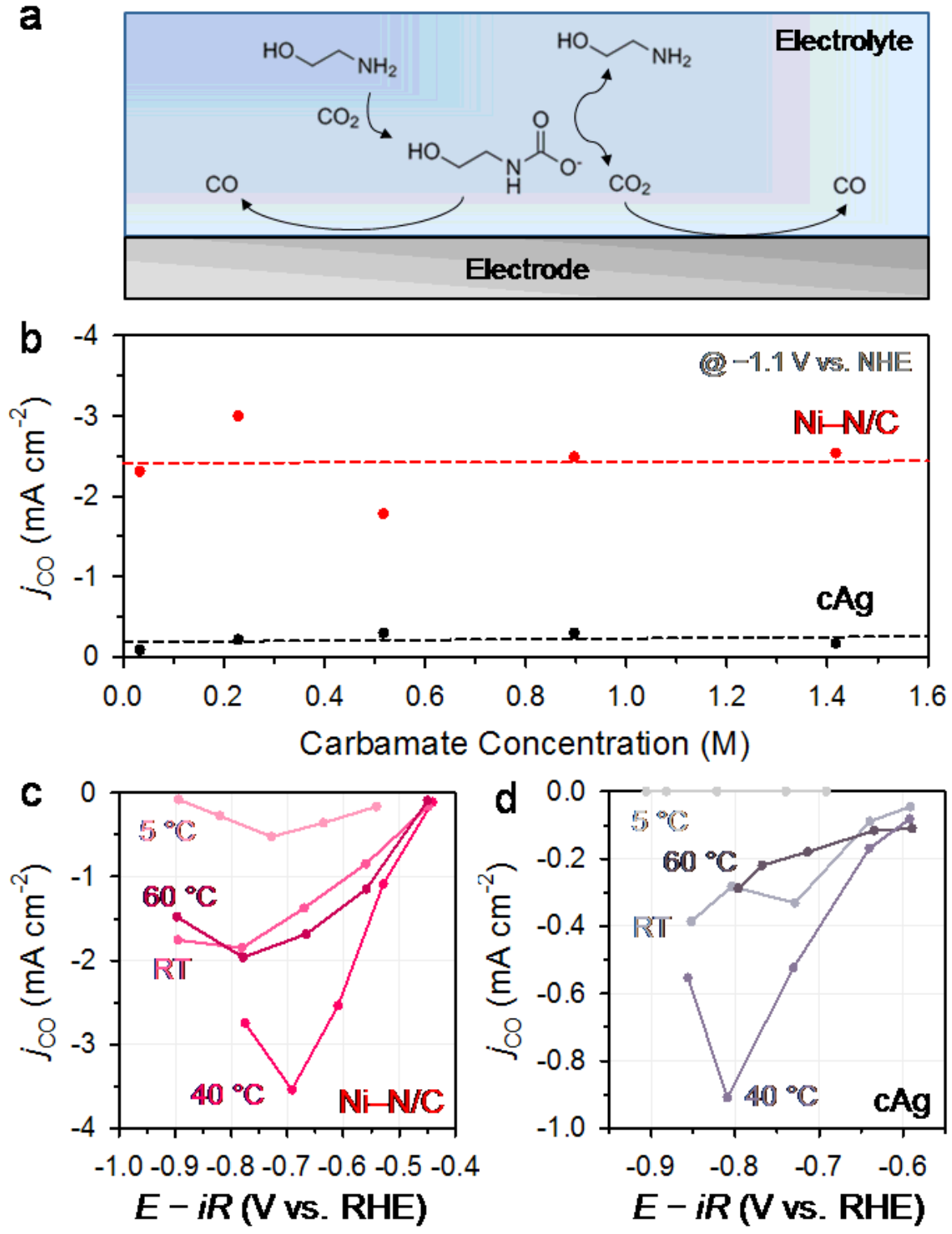

Figure 3

Investigation of the reaction pathway of $\mathrm{CCO}_{2} \mathrm{RR}$. $\mathbf{a}$, Reaction pathways of two possible scenarios. $\mathbf{b}, j_{\mathrm{CO}}$ at $-1.1 \mathrm{~V}$ vs. normal hydrogen electrode (NHE) of $\mathrm{Ni}-\mathrm{N} / \mathrm{C}$ and $\mathrm{cAg}$ for the $\mathrm{CCO}_{2} \mathrm{RR}$ in $\mathrm{CO}_{2}$-adsorbed MEA (1-5 M) solutions with purging Ar. c,d, $j_{\mathrm{CO}}$ of $\mathrm{Ni}-\mathrm{N} / \mathrm{C}(\mathbf{c})$ and $\mathrm{cAg}(\mathrm{d})$ for the $\mathrm{CCO}_{2} \mathrm{RR}$ in $\mathrm{CO}_{2}$-adsorbed $5 \mathrm{M}$ MEA in different temperatures. 

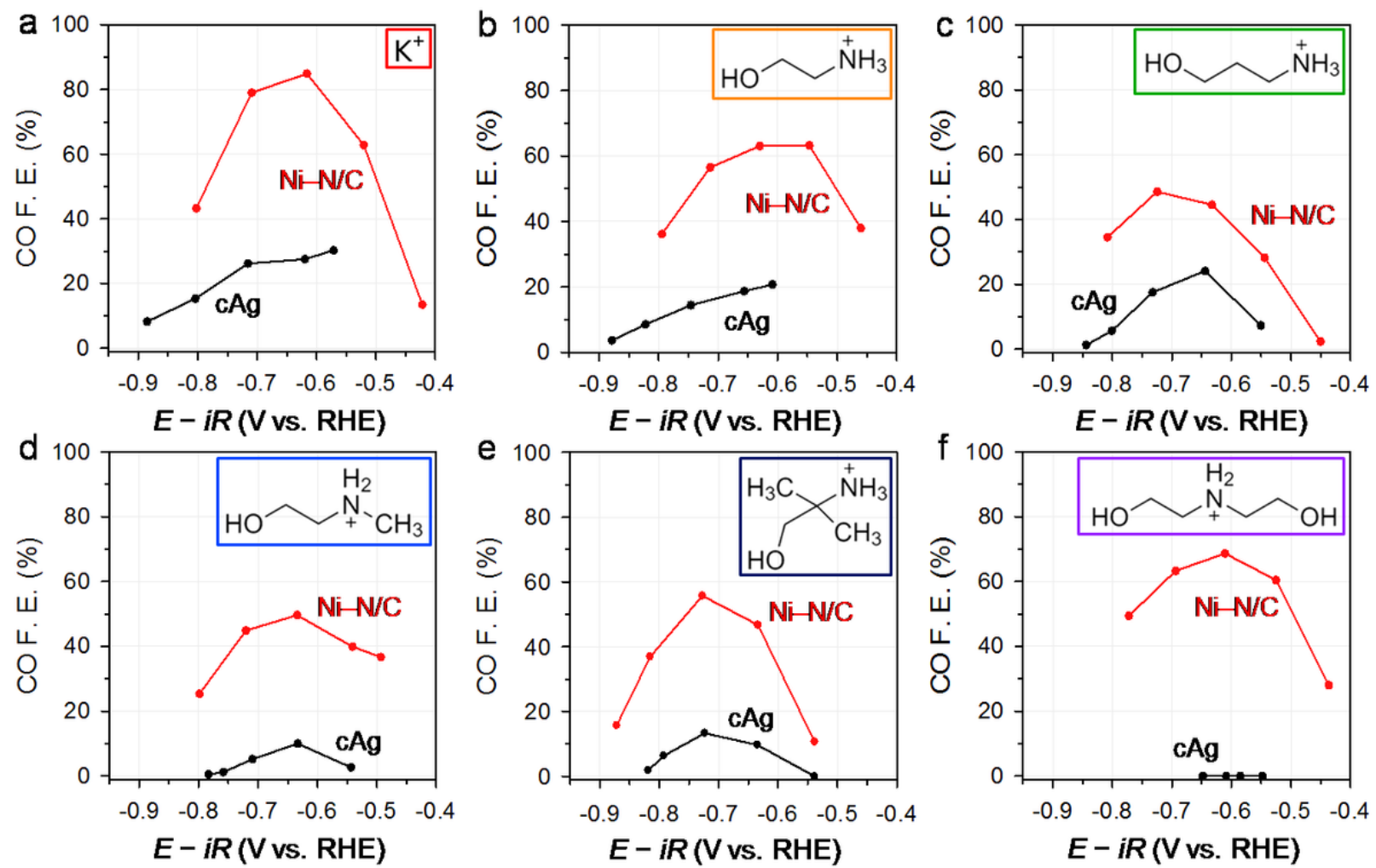

$\mathrm{K}^{+}$
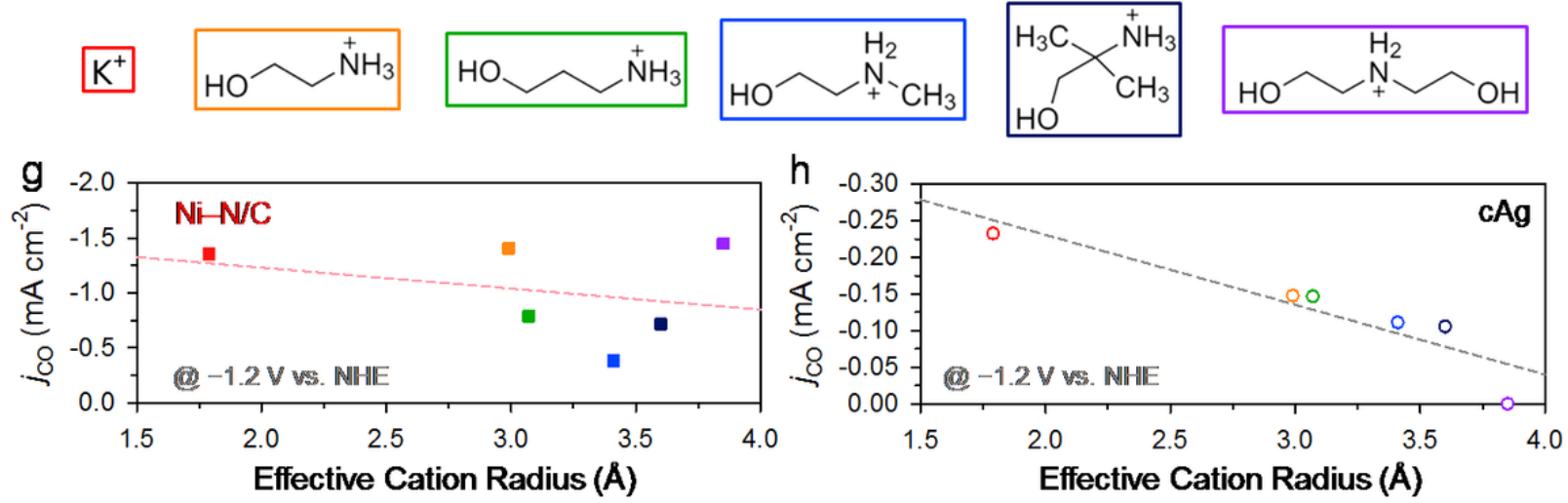

Figure 4

Universality of $\mathrm{Ni}-\mathrm{N} / \mathrm{C}$ in various capturing media for the $\mathrm{cCO}_{2} \mathrm{RR}$. a-f, CO F. E. of Ni-N/C and cAg for the $\mathrm{CCO}_{2} \mathrm{RR}$ in $\mathrm{CO}_{2}$-adsorbed 1 $\mathrm{M} \mathrm{KHCO}_{3}$ (a), 1 M MEA (b), 1 M 3-amino-1-propanol (c), 1 M 2-(methylamino)ethanol (d), 1 M 2-amino-2-methyl-1-propanol (e), and 1 M diethanolamine (f) solutions with purging Ar. g, h, $j_{\mathrm{CO}}$ of Ni-N/C (g) and cAg (h) with respect to effective cation radius at $-1.2 \mathrm{~V}$ vs. NHE. 

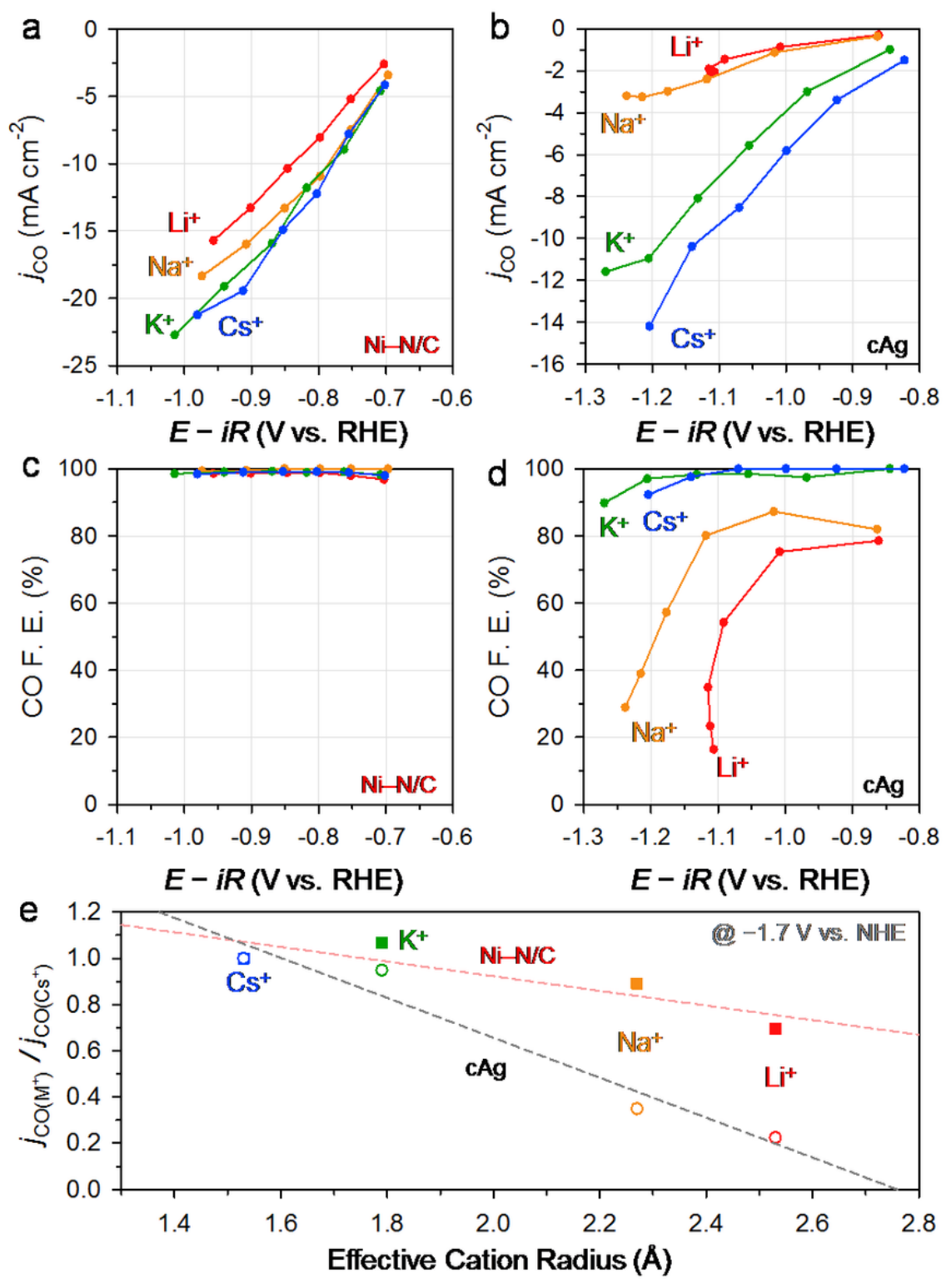

Figure 5

Cation effect and sensitivity of catalysts for conventional $\mathrm{CO}_{2} \mathrm{RR}$. $\mathbf{a}, \mathbf{b} j_{\mathrm{CO}}$ and $\mathbf{c}, \mathbf{d} \mathrm{CO} \mathrm{F}$. E. of Ni-N/C $(\mathbf{a}, \mathbf{c})$ and cAg $(\mathbf{b}, \mathbf{d})$ with the electrochemical $\mathrm{CO}_{2} \mathrm{RR}$ in $0.05 \mathrm{M}$ carbonate electrolytes containing different alkali metal cations. e, Normalized $j_{\mathrm{CO}}$ by $j_{\mathrm{CO}}$ in the presence of $\mathrm{Cs}^{+}$with respect to the effective cation radius at $-1.7 \mathrm{~V} v \mathrm{vs}$. NHE.

\section{Supplementary Files}

This is a list of supplementary files associated with this preprint. Click to download.

- Onlinefloatimage6.png

- 20220128CapturedCO2SISubmission.pdf 